\title{
ANTOLOGÍAS DE POESÍA ARGELINA CONTEMPORÁNEA EN LENGUA ÁRABE
}

IsAac DONOSO

Universidad de Alicante

Emilio Sola y Mohamed Benmebrhout (coords.), País de larga pena... Pequeña antología de la poesía argelina contemporánea (1950

- 1978), Fuengirola, Cuadernos de la Afrobética, 1979, 176 pp. [ISBN: 84-300-1615-5]

SouHel Dib, Anthologie de la poésie populaire algérienne d'expression arabe, París, L'Harmattan, 1987, 160 pp. [ISBN: 2-85802-771-4]

Ahmed LANASRI, Anthologie de la poésie algérienne de langue arabe. Textes arabe et français, París, Publisud, 1994, 242 pp. [ISBN: 286600-439-6]

Jean DÉjeuX, La poésie algérienne. De 1830 à nos jours, París, Publisud, 1996, 109 pp. [ISBN: 2-86600-031-5]

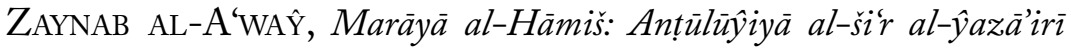
al-mu'āṣir, Argel, al-Faḍā’ al-Ḥurr, 2007, 252 pp. [ISBN: 9-96187431-8]

El papel que una reseña debe de cumplir es la de revisar la actualidad bibliográfica y valorar críticamente el papel de las nuevas publicaciones y su contribución al mejor conocimiento de un campo de estudios. Cuando ese campo de estudios no produce abundantes obras, y el seguimiento crítico es paupérrimo, se hace explicable la necesidad de revisar lo que se ha ido produciendo más allá del pasado inmediato. Y con la consigna de actualizar una serie de antologías poéticas que sobre la literatura argelina contemporánea han ido apareciendo, y vertebrarlas de algún modo para que reflejen una unidad de trabajos como 
fuente para el estudio de esta poesía, realizamos este breve comentario bibliográfico.

Éste es el contexto en el que se encuentra la poesía argelina y, en general, todo aquello relacionado con la literatura realizada en Argelia, país vecino geográfica e históricamente de España, pero del que culturalmente se conoce muy poco. $Y$ no es nuevo este desconocimiento, pues parece habitual que en los libros especializados sobre literatura árabe se afirme el escaso interés que ha despertado la literatura argelina, y lo muy poco que existe accesible al público español en monografías y traducciones ${ }^{1}$. Pero también es habitual igualmente valorar el potencial y las prometedoras perspectivas de futuro que la literatura argelina puede ofrecer al conjunto del mundo árabe:

La literatura argelina, como muchas de las facetas del propio país que las produce, aparece, cara al inmediato porvenir, como una de las más esperanzadoras y susceptibles de importantes hallazgos y realizaciones, dentro del ámbito general de la expresada en lengua árabe [...] En tal sentido, pues, $y$ en cuanto como tal literatura nacional acabe definitivamente de asentarse y hallar su línea propia y característica en el contexto general de la dramática y crítica existencia árabe contemporánea, representará sin duda una muy destacada voz a atender y armonizar, participando activa y decisoriamente en el concierto"2.

${ }^{1}$ Luis Miguel Pérez Cañada, "Panorámica de los estudios y traducciones de literatura argelina en español”, en Gonzalo Fernández Parrilla, Luis Miguel Pérez Cañada y Rosario Montoro Murillo (eds.), Panorámica de los estudios y traducciones de la literatura del Magreb en español, Toledo, Escuela de Traductores de Toledo, 1998, pp. 17-26; y después en "Literatura argelina traducida al español: panorámica", en Gonzalo Fernández Parrilla y Rosario Montoro Murillo (coords.), El Magreb y Europa: literatura y traducción, Cuenca, Universidad de Castilla La Mancha, 1999, pp. 339-352.

${ }^{2}$ Pedro Martínez Montávez, Introducción a la literatura árabe moderna, Granada, Universidad de Granada, 1994, pp. 186-187. 
Las palabras de Montávez, vistas con la perspectiva que da el tiempo, parecen describir agudamente la tendencia contemporánea del mundo árabe hacia la autodestrucción, o la incapacidad, por los motivos que quieran explicar politólogos y sociólogos, de crear sociedades estables en lo político y progresivas en lo económico. Sin duda por motivos de desestabilización e intervencionismo, también por la fragilidad de los estados postcoloniales, lo cierto es que la larga lucha por la independencia que varias generaciones de argelinos han tenido que librar, y el conflicto de identidad y diglosia lingüística que la agresiva política educativa francesa produjo, ha dado a la moderna Argelia un sustrato social e intelectual que favorece, y está favoreciendo, la agitación y la reflexión cultural. Y en efecto estamos asistiendo al encumbramiento de figuras argelinas en la primera línea literaria, tanto en la producción en francés, con Yasmina Khadra, como árabe, con Aḥlām Mustaganamī.

No obstante, lo cierto es que en el ámbito hispánico siguen siendo muy escasos lo trabajos que tienen la cultura argelina como objeto. Y la persona interesada en la literatura argelina cuenta con muy pocas referencias para acercarse a un mundo cultural que está, prácticamente, a la vuelta de la esquina, cruzando unas cuantas millas náuticas. Por todo ello, proponemos hacer en este comentario bibliográfico una pequeña relación sobre antologías de la poesía argelina contemporánea, con especial interés en la producción en lengua árabe, a pesar de que alguna pueda haber superado los años de rigor para formar parte de la actualidad bibliográfica.

Esto es lo que sucede con País de larga pena... Pequeña antología de la poesía argelina contemporánea (1950-1978), prácticamente la única antología disponible para el público hispanohablante sobre la poesía argelina. Lo cierto es que, salvo algunos 
poemas específicos ${ }^{3}$, no encontramos ninguna monografía en español que realice una antología poética argelina. De ahí la importancia de este texto publicado por la iniciativa de Francisco López Barrios y la coordinación de Emilio Sola, profesor español de larga estancia en Argelia. Lo cierto es que el volumen sólo recoge poesía argelina en francés, y anuncia que aparecerá otro segundo volumen con la poesía en árabe. Sin embargo ese segundo volumen prometido es ilocalizable, por lo que hay que suponer que nunca se publicó. Así que en español sólo contamos con este texto de obras en francés, reproducidas de forma paralela en original y traducción española en páginas consecutivas. Al menos se introduce el volumen con una sucinta introducción por Mohamed Benmebkhout, y algunos de los poemas son verdaderamente reveladores de la naturaleza poética argelina. En efecto, frente al conformismo y beneplácito al absorber la lengua del colonizador obedeciendo su discurso de progreso y superioridad cultural, los poetas argelinos denuncian la postración, ruina y letargo al que la educación en francés les condena:

Je n'ai pas de portée pour les notes qui naissent en moi on m’a donné des mots sans âme des mots aux yeux de chien battu.

No tengo un pentagrama

para las notas que nacen en mi. Se me han dado palabras sin alma palabras con ojos de perro apaleado ${ }^{4}$.

${ }^{3}$ Como los aparecidos en Leonor Martínez Martín, Antología de la poesía árabe contemporánea, Madrid, Austral, 1972, pp. 212-218, los que se anotan en Pérez Cañada, loc. cit., y quizá alguno que se nos haya pasado.

${ }^{4}$ Emilio Sola y Mohamed Benmebkhout (coords.), op. cit., p. 91. 
Este fragmento perteneciente al poema "Prefacio" de Boualem Khalfa muestra que los argelinos no asumen el francés de forma inconsciente y pasiva, sino que la intervención lingüística, la extirpación del propio patrimonio cognitivo y sustitución por otro impuesto, el lavado de cerebro, la visceralidad de la ingeniería cultural, y el cinismo de luchar contra el analfabetismo creando legiones de analfabetos en su propia lengua materna, no es un favor al cual van a dar las gracias. El poeta argelino, alienado, podrá escribir "palabras sin alma" en francés, pero mostrará igualmente su ira, la rabia de los ojos del perro apaleado. Lo mismo dirá Rachid Boudjedra: "¿Para qué sirven mis poemas, / si mi madre no sabe leer?". Y lo mismo dice Hamid Skif: "Nos engañaron / como se engaña a la bestia al acecho / como se engaña a niños tiernos / como se engaña a clientes tontos". Frente a otras literaturas mal llamadas "postcoloniales" - en otro juego cínico de la crítica literaria occidental, que quiere seguir perpetuando el hecho colonial y la centralidad del colonizador-, la literatura argelina no muestra pleitesía y avenencia con la lengua del colonizador, y denuncia, irasciblemente, la invalidez intelectual a la que le ha querido reducir el francés, a pesar de escribir en francés, precisamente por poder sólo escribir en francés.

El segundo texto explícitamente anuncia en su título que las obras antologadas tienen un original árabe. Sin embargo, y lamentablemente, todo el texto se reproduce en francés, sin añadir el original árabe en ningún lugar. Lo peor de todo ello es que no se trataba de textos en árabe clásico, sino precisamente en dialectal argelino, razón de más para obligadamente haber añadido las versiones originales. En efecto, Anthologie de la poésie populaire algérienne d'expression arabe de Souhel Dib, es un texto que deja al lector algo contrariado ya que, siendo una antología de poesía popular — en donde la lengua no tiene por qué reducirse a la norma culta, y el principal interés radica pre- 
cisamente en recoger esa muestra de lengua, como patrimonio intangible en peligro de desaparición-, no reproduce las fuentes. Y el objeto de esta antología no podría haber sido otro que el de reproducir las interesantes muestras de lengua árabe de los originales. En fin, esta ausencia no se explica convincentemente en la introducción, y lo que tenemos es una sucesión acrónima de poemas en francés organizados por temas: poesía religiosa, erótica, sátira y de combate, y elegíaca. Decimos acrónima porque tampoco se indican claramente los periodos que comprenden los poemas, seguidos uno tras otro en un todo, que va desde el siglo XVI al XX. Es decir, el lector no puede hacerse una idea del proceso estético o histórico en el que se desarrolla esta poesía, más allá de la descripción y adscripción a unos géneros poéticos tradicionales. Como colofón, de los autores antologados se reproduce al final del volumen unas pequeñas notas biográficas, sin indicarnos las fuentes de donde se extraen los datos.

El resultado de todo ello se asemeja bastante a las estrategias culturales de países colonizados a la hora de transvasar en la lengua del colonizador el patrimonio oral y popular (es decir, el que constituye la forja de un pueblo, según el ideario romántico-nacionalista) de la lengua que se quiere culturalmente sustituir. No obstante, la obra sí que ofrece elementos interesantes, y las notas que apuntamos quieren abundar en que, más favor se le hubiera hecho al objeto de estudio —en este caso la poesía popular argelina en lengua árabe-, reproduciendo los originales y analizando directamente su naturaleza, más que reproduciendo una sucesión de poemas en francés descontextualizados. Pero sin duda sí es relevante lo que menciona Souhel Dib en su introducción, en torno al origen de esta poesía argelina, y la relevancia del elemento andalusí:

La poésie d'origine andalouse va s'enrichir de nuances nouvelles, traduisant le tempérament d'un type d'homme issu 
des syncrétismes andalous et autochtones [...] Dans un premier moment, la floraison de la poésie érotique est due au lyrisme directement hérité des cours de Grenade, de Séville et de Cordoue ${ }^{5}$.

Quizá de nuevo hubiera faltado abundar con más documentación que pudiera reflejar esa supuesta y determinante influencia andalusí. En cualquier caso, dada la escasez bibliográfica sobre el tema, la obra de Dib al menos es un primer elemento del que se pueden extraer datos para seguir reconstruyendo el objeto de estudio.

El tercer volumen antológico que vamos a comentar por fin nos ofrece textos en original árabe más traducción francesa, reproducidas primero las traducciones, después los originales: Anthologie de la poésie algérienne de langue arabe. Textes arabe et français, obra de Ahmed Lanasri. Aunque el título no lo expresa explícitamente, toda la poesía recogida pertenece al periodo moderno y contemporáneo, y no a textos de la poesía árabe histórica realizada en suelo argelino. La obra divide en tres etapas la poesía contemporánea: Renacimiento, Renovación y Liberación. Aunque no se define en los enunciados una clara separación cronológica, el periodo de Renacimiento comprendería la Nahda árabe hasta el comienzo de los años 20, la etapa de Renovación sería el periodo de entreguerras y el preludio de la revolución argelina, y la etapa de Liberación las últimas fases de la guerra de liberación, la independencia en 1962 y las primeras décadas del nuevo Estado argelino.

Tras una breve pero completa introducción de los tres periodos, se reproducen los poemas en traducción francesa divididos también en tres secciones, seguidos de las versiones originales en árabe, igualmente divididas en tres secciones ( $\check{S}_{i}$ r al-nahḍ, Šir al-Tâydìd, Šír al-Taḥrīr), con anotación de la fuente de la

${ }^{5}$ Souhel Dib, op. cit., p. 10. 
cual se extrae el texto árabe. En la sección francesa, cada autor es introducido por una glosa biográfica y, en general, de cada autor se reproducen dos o tres poemas. Se trata por lo tanto de un libro muy valioso, ya que anota las fuentes de los originales árabes y los reproduce, con la importancia que ello tiene para la poesía árabe moderna, ya que permite visualizar rápidamente el proceso de descomposición de la casida clásica. En fin, la obra de Lanasri es una antología esencial dentro de la escasa bibliografía sobre la poesía argelina en árabe.

También divide en tres periodos la poesía argelina la siguiente obra que reseñamos (1830-1920; 1920-1945; después de 1945), que no es tanto una antología como una panorámica crítica de la historia de la poesía argelina contemporánea, sobre todo francesa, pero también árabe: La poésie algérienne. De 1830 à nos jours. $\mathrm{Y}$ ahí tal vez radica la importancia de reseñar este libro, obra de Jean Déjeux, uno de los principales críticos de la literatura magrebí de expresión francesa y de los defensores de su valoración nacional. En efecto, a pesar de no ser una antología, creemos que es necesario resaltar esta obra como prueba de la transformación que la crítica francesa ha ido experimentando, abandonando los apriorismos del estudio del hecho literario en términos postcoloniales. La literatura puede ser un hecho político, pero es sin duda un hecho artístico. Reducir el estudio literario de la creación en una lengua impuesta al colonizado, desde el punto de vista del colonizador, desde su ámbito cultural, comodidad institucional y difusión editorial, es seguir perpetuando la herida del proceso de desarraigo cultural fruto del intervencionismo colonial. En otras palabras, no sólo es necesario, sino conditio sine qua non, que el estudio de las literaturas surgidas en la lengua del colonizador se estudien desde la perspectiva de aquel que asume una nueva lengua para crear una nueva realidad. Hay que ir más allá del plano colonizador-colonizado, para asumir una ecuación hegeliana en la que ambos 
términos crean algo nuevo, algo válido para la nueva realidad creada. La Argelia de 1830 no es la misma Argelia de 1962, y es además imposible volver a un momento previo. El estudio del hecho literario debe asumir por lo tanto el análisis de los procesos culturales per se, sin falacias, ideologías o esencialismos que coarten su naturaleza sintética.

Creemos que Jean Déjeux se ha ido acercando a estos planteamientos, y de algún modo asume el proceso de adopción del francés como lengua empleada para producir literatura por una parte de la población argelina, y estudia al mismo tiempo el desarrollo de la creación en árabe dentro de este contexto de transformación cultural. Así, concluye su estudio haciendo frente a la gran cuestión: "Le problème de l'expression française", la cual resuelve haciendo hablar a los propios argelinos, que sean ellos los que den respuesta a por qué emplean el francés. $Y$ añade un elemento con el que busca ejemplificar ese proceso de síntesis, el del uso de la poesía por parte de una comunidad árabe como voz de la comunidad, como voz de la tribu frente al enemigo, aunque sea en la lengua del propio enemigo:

Dès 1830 , nous voyons le poète au premier rang pour exprimer les sentiments profonds de ses compatriotas, au rythme des événements et au niveua des tribus dispersées ou même de toute l'Algérie investie. Le poète contemporain d'expression française assume le même rôle. Mais il n'oublie pas qu'il sait aussi chanter d'autres thèmes que ceux de l'homme-révolté6.

No obstante, como podemos leer, Déjeux va más allá de reducir el hecho poético a la voz del pueblo. La poesía no puede ser un mero vocero político, sino que sobre todo es voz de la expresión individual. De ahí que el problema de la poesía argelina

${ }^{6}$ Jean Déjeux, op. cit., p. 91. 
en francés, más allá de la independencia política, deba enfrentarse a la identidad individual.

Finalmente vamos a hablar de la obra más reciente en el tiempo y que alcanza de algún modo los parámetros que el objeto de estudio estaba demandando: poder tener una obra referencial con las principales composiciones poéticas contemporáneas argelinas en lengua árabe. Se trata del libro de Zaynab al-

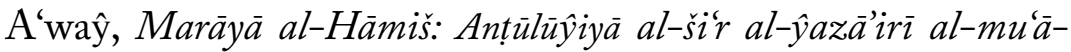
sir / مرايا الهامش: انطولوجيا الشعر الجزائرى المعاصر : "Espejos al margen: Antología de la poesía argelina contemporánea". Su autora es poeta argelina y profesora en el departamento de árabe de la Universidad París 8. El libro responde a las líneas de la antología de la novela árabe argelina publicada en la misma casa editorial por Wāsīnī al-A'raŷ, y de la que hablaremos en otro trabajo. Se trata de hacer accesibles al gran público las grandes obras de la literatura argelina en lengua árabe. Se trata por lo tanto de crear un canon literario sobre la clasicidad de una literatura, sin duda ya nacionalizada tras varias décadas de independencia y de oficialidad de la lengua árabe, y de una literatura que se constituye ya no como una promesa, sino como una auténtica realidad dentro del mundo árabe. A partir de aquí, ya depende de nosotros querer saber más o menos sobre la capacidad creativa de nuestros vecinos del sur, herederos del legado andalusí, y uno de los principales motores actuales de la modernidad árabe. 


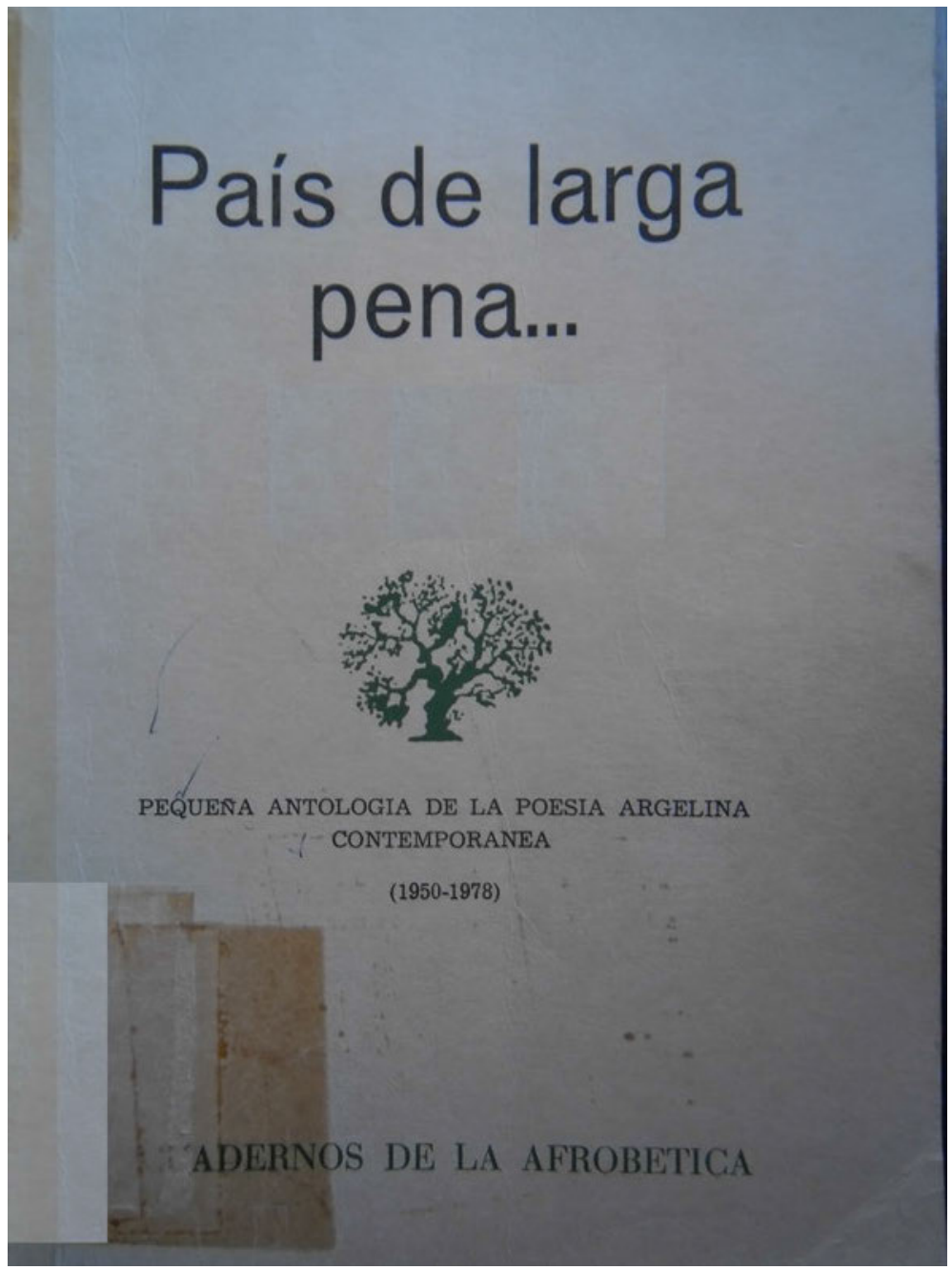



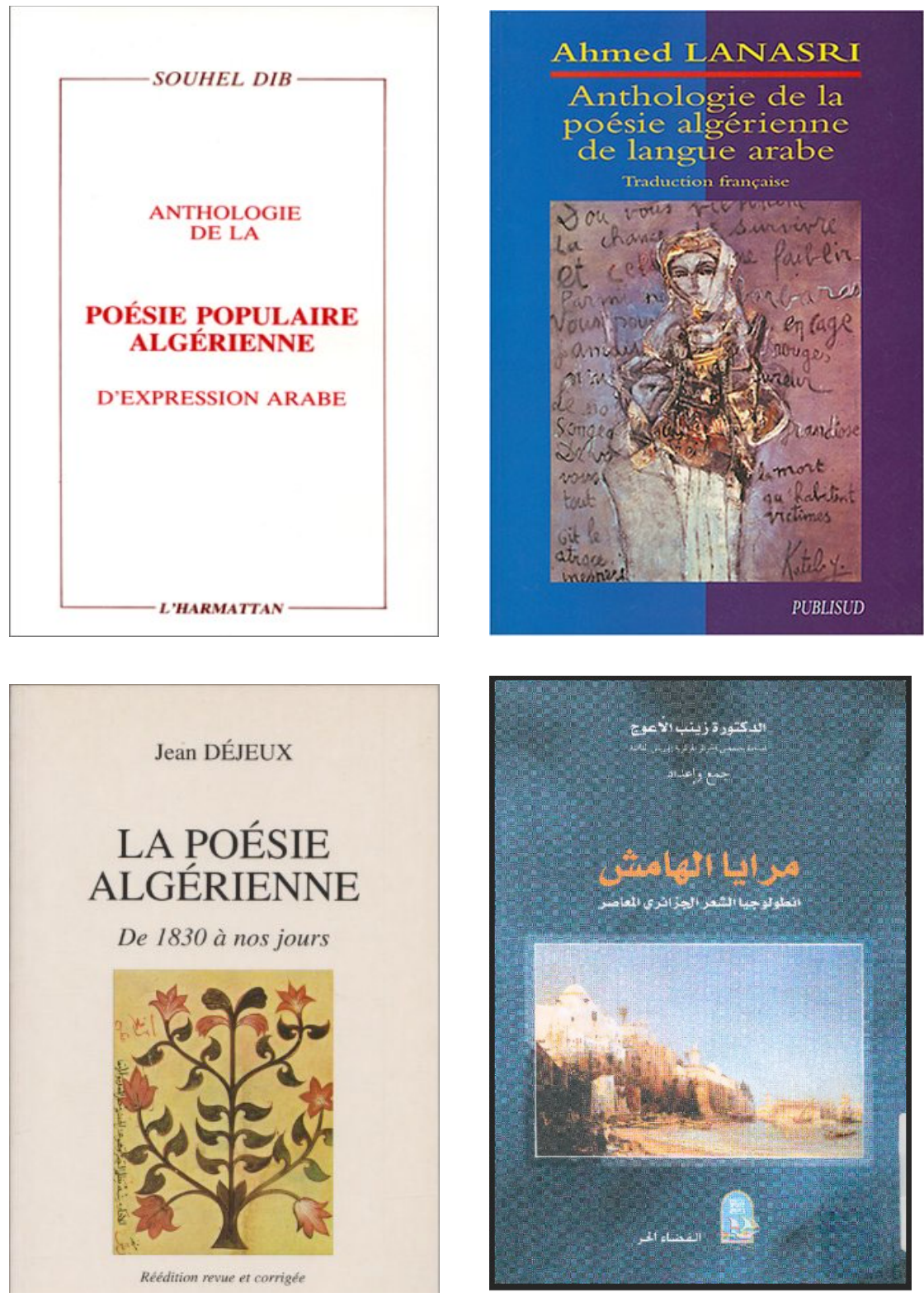